\title{
O gênero fanfiction: análise intergenérica da escrita de fãs
}

DOI: http://dx.doi.org/10.21165/el.v49i2.2517

\author{
Karen Dias de Sousa'
}

\section{Resumo}

Este artigo pretende demonstrar os resultados de uma pesquisa que analisou textos publicados em uma plataforma on-line de fanfics, narrativas criadas por fã da cultura pop japonesa. A análise utilizou-se principalmente do conceito de "relações intergenéricas" e da noção de "ruína" (CORRÊA, 2006) para investigar com quais gêneros, esferas e semioses as fanfics dialogam.

Palavras-chave: fanfictions; intergenericidade; gênero discursivo; escrita.

1 Universidade Estadual de Campinas (UNICAMP), Campinas, São Paulo, Brasil; karen_kido@hotmail.com; https://orcid.org/0000-0002-5506-9019 


\title{
The fanfiction genre: writing intergeneric analysis of fan writing
}

\begin{abstract}
This article intends to demonstrate the results of a research that analyzed texts published in an online platform of fanfics, which are narratives created by fans of Japanese pop culture. The analysis used mainly Corrêa (2006) concepts of intergenericity and "ruin" to investigate with which genres, spheres and languages the fanfics dialogue.
\end{abstract}

Keywords: fanfictions; intergenericity; discursive genre; writing.

\section{Introdução}

Neste artigo, será investigada a escrita no meio digital por meio da análise intergenérica de fanfictions (ou fanfics), histórias criadas por escritores não profissionais que publicam na internet. A maior parte dessas fanfics tem como ponto de partida textos escritos por outros autores e são baseadas em enunciados vindos dos mais diversos contextos de produção: letras de músicas, romances, poemas, produções audiovisuais das mais variadas, revistas em quadrinhos, entre outros. Embora existam fanfics escritas a partir de textos literários, por exemplo, elas estão, majoritariamente, vinculadas à cultura pop e à cultura de massa hegemônica.

A escrita desses textos costuma estar relacionada ao desejo de um fã de dar continuidade a uma história, de criar novos enredos para tramas já existentes e ver seus personagens favoritos em ação novamente. Exatamente por isso, as fanfics geralmente são textos com forma composicional narrativa. No entanto, como será demostrado posteriormente, elas podem assumir outras formas composicionais, se aproximando, por exemplo, da poesia, da canção e de outros gêneros.

Como as fanfics são inspiradas nos mais diversos formatos midiáticos que a cultura pop oferece a seu público, desde animações até as canções da moda, elas acabam se envolvendo numa rede complexa de relações com outros gêneros e discursos. Ou seja, embora esses textos sejam uma manifestação da linguagem verbal, eles dialogam explicitamente com outras linguagens e, justamente por isso, mantêm marcas bastante visíveis dessas outras linguagens em sua constituição. Portanto, pode-se dizer que as fanfics são textos representativos do envolvimento da escrita verbal com outros textos multissemióticos e do diálogo com diferentes gêneros.

As plataformas on-line onde são publicados esses textos são ambientes em que a escrita se desenvolve de maneira peculiar. Leitores e escritores navegam por esses espaços digitais participando ativamente da construção de sentidos e de novos gêneros que 
surgem nesse contexto. Na maioria das plataformas, qualquer pessoa na internet pode ler os textos e há, geralmente, espaços para comentar e interagir com escritores e outros leitores da comunidade. Quando um texto é publicado nesses ambientes, a comunidade lê, avalia, opina e dá sugestões sobre a escrita. Isso faz com que os textos que circulam nesses espaços tenham como característica a colaboração e a participação (JENKINS, 1992; 2008), ou seja, o processo de criação das fanfics é feito quase concomitantemente à leitura. Assim que o escritor recebe um feedback de um capítulo de sua história, ele pode refletir sobre sua escrita e levar ou não em consideração as críticas para o próximo capítulo.

Esta pesquisa tem como objetivo geral compreender como acontece o diálogo entre as fanfics e outros gêneros (análise intergenérica), assumindo essas narrativas como gêneros emergentes associados, muitas vezes, a outras semioses, esferas e culturas. Considerando que, segundo Bakhtin (2011 [1978]), o gênero é constituído por forma composicional, tema e estilo, a análise será realizada levando-se em consideração esses três elementos, para que haja uma melhor compreensão de como acontecem esses diálogos conforme uma organização analítica pautada no método sociológico².

Este artigo pretende, desse modo, colaborar com os estudos sobre escrita, gêneros e novas tecnologias pelas lentes analíticas do dialogismo intergenérico. As observações feitas nesse ambiente podem ajudar a entender a complexidade dos processos de escrita que acontecem em ambientes que podem ser considerados não convencionais para aqueles acostumados à cultura do impresso. Essas práticas de leitura e escrita diferenciadas, marcadas por um novo ethos, estão se expandindo há poucas décadas, por isso são caracterizadas como "novas" por diversos autores. No entanto, é importante enfatizar que outras mudanças importantes na relação sujeito/discurso já estão em curso, propiciadas pelas tecnologias, o que é bem próprio da época de grandes transformações sociais e culturais em que vivemos.

\section{Fundamentação teórica}

Para o desenvolvimento da pesquisa, foram usados dois conceitos formulados pelo Círculo de Bakhtin, o gênero do discurso e o dialogismo, além dos conceitos de intergenericidade e "ruína", desenvolvidos por Corrêa $(2006,2007,2010)$ para tratar do diálogo entre gêneros do discurso. A seguir, cada um deles será discutido.

20 método sociológico, proposto pelo Círculo de Bakhtin, surgiu em oposição aos métodos tradicionais de análise linguística, que recaiam frequentemente em um "objetivismo abstrato" (VOLOCHINOV, 2017, p. 241) e desconsideravam o fenômeno da enunciação como interação social. Assim, no método sociológico, procura-se problematizar questões a respeito do discurso alheio na palavra do sujeito e da construção de sua significação como ato responsivo. 


\section{0 gênero discursivo}

Para Bakhtin (2011 [1978]), todo enunciado está circunscrito em um campo (ou esfera) da atividade humana e este impõe determinadas condições que conduzirão aos diferentes lugares sociais ocupados por esse enunciado. Assim, por exemplo, na esfera literária, as apreciações de um texto serão muito diferentes daquelas da esfera acadêmica, pois a primeira está ligada à fruição estética, enquanto a segunda à apresentação dos resultados de uma pesquisa.

Dessa forma, segundo Bakhtin (2011 [1978], p. 361), os enunciados

[...] refletem as condições específicas e as finalidades de cada referido campo, não só por seu conteúdo (temático) e pelo estilo da linguagem, ou seja, pela seleção dos recursos lexicais, fraseológicos e gramaticais da língua, mas, acima de tudo, por sua construção composicional.

Os gêneros do discurso são definidos por Bakhtin (2011 [1978], p. 262) como tipos apenas "relativamente estáveis" de enunciados, o que aponta para a dificuldade de delimitar suas fronteiras, pois

[...] a riqueza e a diversidade dos gêneros do discurso são infinitas porque são inesgotáveis as possibilidades da multiforme atividade humana e porque em cada campo dessa atividade é integral o repertório de gêneros do discurso, que cresce e se diferencia à medida que se desenvolve e se complexifica um determinado campo.

Sendo os gêneros orientados a partir da esfera e da situação concreta de comunicação, eles se constituem em forma composicional, tema e estilo. No entanto, essas três dimensões não podem ser entendidas como partes independentes do gênero que não se relacionam entre si. A separação que Bakhtin faz é meramente conceitual e é apenas por questões de organização da análise que, neste artigo, elas serão abordadas separadamente.

A forma composicional, segundo Sartori (2008, p. 76), "não é uma simples estrutura '(ir) repetível' nos diversos gêneros, já que nela há um sistema de valores do autor-criador sendo realizado". E isso é mais visível quando se trata de gêneros mais flexíveis, como é o caso das fanfics, que estão mais ligadas à esfera do entretenimento, já que elas podem assumir diferentes formas composicionais. Conforme explica Sartori, o tema também é determinado pela posição axiológica dos sujeitos, de acordo com o lugar social que ocupam. 
Bakhtin (2011 [1978]) explica que o estilo individual pode aparecer em qualquer gênero, no entanto, há alguns em que o autor tem mais liberdade para deixar aparecer suas marcas no texto, e há ainda aqueles em que é fundamental que essa individualidade apareça, como no caso dos gêneros literários. Em outros gêneros, como os da esfera jurídica, o que fica mais evidente é o estilo do gênero, que se sobrepõe ao individual. O autor (2011 [1978]) critica análises de estilos que se concentram unicamente em realizar uma simples descrição, sem considerar o âmbito de produção do enunciado. Para Bakhtin (2011 [1978]), é necessário que se leve em conta os aspectos específicos do gênero e que seja concebido como expressão da relação entre sujeito e seus possíveis interlocutores. Neste artigo, será abordado apenas o estilo do gênero fanfic nos dados, pois para a análise do estilo individual seria necessário ter um olhar analítico para o sujeito e sua constituição como escritor, algo que não é proposto neste texto e que foge aos seus objetivos.

\section{0 dialogismo bakhtiniano}

Bakhtin (2011 [1978]) concebe a linguagem como sendo dialógica. Segundo o autor (2011 [1978], p. 323), "as relações dialógicas são relações (semânticas) entre toda espécie de enunciados na comunicação discursiva". Faraco (2009), remetendo à obra de Bakhtin, diz que não se trata de uma concepção restrita de diálogo, como a interação face a face, ou a simples referência ao discurso do outro explicitamente, mas de um modo de entender como é o funcionamento dos enunciados na língua.

Esse funcionamento diz respeito ao fato de todo enunciado se reportar a outro dito anteriormente, ao mesmo tempo em que antecipa e espera uma resposta. Desse modo, o discurso é fundamentalmente heterogêneo, no sentido de que "é uma articulação de múltiplas vozes sociais [...] é o ponto de encontro e confronto dessas múltiplas vozes. Essa dialogização interna será ou não claramente mostrada, isto é, o dizer alheio será ou não destacado como tal no enunciado" (FARACO, 2009, p. 60).

Há, portanto, várias maneiras de um enunciado dialogar com outro, que dependerá, principalmente, da posição que o sujeito assume diante dos outros enunciados que circulam socialmente, que pode ser tanto de concordância ou discordância, já que não necessariamente o diálogo implica o consenso com o discurso alheio, conforme explica Faraco (2009, p. 69, grifos do autor):

[...] o diálogo, no sentido amplo do termo ("o simpósio universal"), deve ser entendido como um vasto espaço de luta entre as vozes sociais (uma espécie de guerra dos discursos), no qual atuam forças centrípetas (aquelas que buscam impor certa centralização verboaxiológica por sobre o plurilinguismo real) e forças centrífugas (aquelas que corroem continuamente as tendências centralizadoras, por meio de vários processos dialógicos, tais como, a paródia e o riso de qualquer natureza, a ironia, a polêmica explícita ou velada, a hibridização ou a reavaliação, a sobreposição de vozes etc.). 
É, portanto, através do posicionamento axiológico frente aos mais diversos enunciados que circulam socialmente que o sujeito constrói uma rede de relações de sentido e se constitui como sujeito que fala e escreve. Como bem salienta Faraco (2009, p. 84), ao comentar a noção de dialogismo

[...] é nessa atmosfera heterogênea que o sujeito, mergulhado nas múltiplas relações e dimensões da interação socioideológica, vai se constituindo discursivamente, assimilando vozes sociais e, ao mesmo tempo, suas interrelações dialógicas. É nesse sentido que Bakhtin diz, figurativamente, que não tomamos nossas palavras do dicionário, mas dos lábios dos outros.

Pode-se dizer, portanto, que, como cada sujeito se posiciona de maneira diferente frente à grande quantidade de enunciados que circulam nas várias esferas da atividade humana, cada sujeito é único e seu enunciado nunca é uma mera repetição ou reprodução dos discursos alheios. Aquele que fala ou escreve se constitui como sujeito principalmente na medida em que elabora seus próprios meios para dialogar com o mundo.

Por outro lado, Marchezan (2010, p. 118), ao examinar o conceito de dialogismo, enfatiza o fato de que os "diálogos sociais não se repetem de maneira absoluta, mas não são completamente novos, reiteram marcas históricas e sociais, que caracterizam uma dada cultura, uma dada sociedade". O conceito deve ser entendido, portanto, como inseparável da história, e circunscrito dentro de práticas sociais permeadas por uma ideologia e uma concepção de mundo.

\section{Intergenericidade e Ruína}

Corrêa, pesquisador que se vale das teorias bakhtinianas em seus trabalhos, especialmente da noção de diálogo, trata, em diversas pesquisas, da noção de intergenericidade, ou seja, do diálogo entre os gêneros. Além desse conceito, outro fundamental para o autor é a característica intrinsecamente heterogênea da escrita que pode se manifestar por meio do que o autor chama de "ruínas".

Corrêa (2010) argumenta sobre essa heterogeneidade apontando algumas características da noção de letramento que demonstram a indissociabilidade entre escrita e oralidade. A primeira delas é que essa noção deve ser entendida sempre no plural, como "letramentos", já que há diferentes práticas, inclusive orais, que podem ser vinculadas à prática de escrita. Como exemplo, pode-se citar a contação de histórias realizada por adultos para crianças não alfabetizadas. Por meio da oralidade, a criança consegue acessar o mundo da palavra escrita e participar de muitas práticas letradas. Assim, a escrita não pode ser desvinculada de sua relação com a oralidade. 
Além disso, a heterogeneidade da escrita, segundo o autor, é algo já estabelecido em sua própria gênese, visto que a escrita, diferente de outras práticas de representação simbólica, não é independente da oralidade, como é o caso do desenho e do gesto, por exemplo. Para o autor, a relação que os gêneros escritos mantêm com a oralidade é, portanto, algo constitutivo e inerente a eles. A ideia do autor pode ser confirmada pela possibilidade de as mudanças na oralidade desencadearem transformações na escrita com o passar do tempo (palavras ou expressões novas, mudanças na sintaxe etc.).

Finalmente, conforme o autor, o fato de a escrita e a oralidade não circularem em espaços sociais privativos, mas, pelo contrário, de haver um cruzamento entre essas práticas nos lugares em que são concretizadas, demonstra o quanto é inadequado conceber a escrita de maneira autônoma e dissociada da oralidade, já que essas duas manifestações da língua não aparecem estanques nas esferas sociais.

Desse modo, gêneros orais e escritos dialogam constantemente, assim como gêneros de diversas semioses, que é exatamente o que se pretende demonstrar neste artigo. Produções áudio visuais com recursos gráficos e imagens fazem parte do cotidiano de pessoas que convivem com a complexidade da forma desses enunciados.

Posto isso, o autor, defendendo uma concepção de texto "como registro do processo de sua constituição" (CORRÊA, 2010, p. 630), propõe que a análise intergenérica é uma maneira eficiente de resgatar a história da relação construída entre os gêneros escritos e os gêneros de outras linguagens. Exatamente por isso, o analista deve olhar para o texto observando o fato de que sua materialidade fornece indícios de diálogos.

Corrêa (2006) mostra como os diálogos intergenéricos marcados na escrita podem ser verificados por meio de uma análise que considere os pequenos vestígios presentes nos enunciados, ou seja, a partir de uma análise indiciária, seria possível recuperar resquícios de outros gêneros que aparecem nos textos, denominados pelo autor (2006) como "ruínas".

Consideradas por Corrêa (2006) como vestígios de gêneros discursivos, as ruínas são fragmentos de outros gêneros que se impõem na materialidade dos textos em forma de respostas genéricas a outros enunciados. A palavra não é usada no sentido negativo pelo autor, como algo morto, envelhecido ou destruído, mas como uma parte do discurso que guarda reminiscências dos conhecimentos de uso da linguagem dos sujeitos. 0 autor mostra como as ruínas são frequentemente compreendidas pela escola como erros que precisam ser eliminados do texto, desprezando-se, assim, todo o repertório de conhecimento linguístico do estudante baseado em suas experiências com outros gêneros, inclusive orais, minando, desse modo, as possibilidades de compreender os processos de escrita e a história de sentidos que uma ruína carrega. 
Corrêa (2010) explica que a questão da intergenericidade aparece em Bakhtin principalmente quando são tematizados os gêneros primários e secundários. Segundo Bakhtin (2011 [1978], p. 263),

\begin{abstract}
Os gêneros discursivos secundários (complexos - romances, dramas, pesquisas científicas de toda espécie, os grandes gêneros publicísticos, etc.) surgem nas condições de um convívio cultural mais complexo e relativamente muito desenvolvido e organizado (predominantemente o escrito) - artístico, científico, sociopolítico, etc. No processo de sua formação eles incorporam e reelaboram diversos gêneros primários (simples), que se formaram nas condições da comunicação discursiva imediata.
\end{abstract}

No entanto, Corrêa (2010, p. 644) afirma que o conceito de intergenericidade refere-se à relação "não apenas entre gêneros primários e secundários, mas em princípio, entre quaisquer gêneros do discurso". Portanto, embora a principal preocupação de Corrêa seja com a relação entre gêneros orais e escritos, o autor admite que a intergenericidade não acontece apenas entre essas duas linguagens. Dessa forma, a noção de gênero desenvolvida pelo autor remete a uma noção muito mais flexível, dinâmica e híbrida. Podemos, portanto, defender que ela também pode ocorrer entre a escrita e a imagem, ou a escrita e a música, por exemplo, sendo possível, assim, que ruínas de diferentes semioses participem do processo de escrita.

Corrêa elabora muitas de suas reflexões sobre a intergenericidade e a heterogeneidade da escrita baseado em estudos que tratam das práticas letradas na escola e em contexto acadêmico. Dentre as observações feitas pelo autor, destaca-se a seguinte:

Se vistos como registros da relação que o sujeito mantém com o já-dito, e não, simplesmente, como marcas de fragmentação ou de falta de coerência, podemse levantar hipóteses sobre as relações intergenéricas (BAKHTIN, 1992) que, em jogo na construção textual, marcam uma história de contato com o já-falado/ escrito. Como resultado, o encontro entre prática de pesquisa e ensino pode, pois, ser exemplificado pelo acesso à história de relação do escrevente com o já-falado/escrito, já que auxilia na tomada de decisões didáticas em sala de aula. (CORRÊA, 2010, p. 626).

Ampliando a reflexão proposta por Corrêa (2010), o resgate da história do escrevente com esse "já dito" materializado no texto parece ser interessante para entender também as práticas de escrita que circulam na internet e como os textos desse meio partem de pressupostos, ou como diria Corrêa (2011), de "presumidos" sobre gêneros e linguagens que circulam na mídia de uma maneira diferente de como eram concebidos antes do advento das novas tecnologias. Como exemplo, pode-se citar a própria noção de autoria, que dentro das esferas acadêmica, escolar e artística é entendida como o detentor único 
de uma obra original. Nas fanfics, esse "presumido" não é válido, pois os escritores não necessariamente criam obras inéditas. Por isso, tentar entender essas relações entre os gêneros escritos e outras linguagens, assim como a história do texto com o já-dito, pode esclarecer como a comunidade de fãs constrói sentidos, sem julgar as fanfics como uma escrita desonesta, menor ou grosseira simplesmente porque não trata da autoria da mesma forma que outras esferas tradicionalmente lidam. Sobre esse aspecto, Corrêa (2007, p. 209) também defende que

Quando, na produção do texto, nos distanciamos minimamente dos estereótipos dos campos jurídico e administrativo, os quais marcam uma relação mais cristalizada entre os interlocutores e, por isso, uma fixação de modelos mais duradoura, deparamo-nos com o dinamismo da linguagem. É com esse dinamismo que a heterogeneidade da escrita permite trabalhar. Isso se ela não for vista, redutoramente, como inadequação ou erro.

O gênero, portanto, não é entendido como algo estático ou imutável, com formas fixas e rigidamente controladas: ele mantém relação direta com as esferas da atividade humana e também com a cultura, já que, historicamente, cada comunidade cria suas próprias formas "relativamente estáveis" de dizer. A questão é como esses gêneros se aproximam, se hibridizam, e disputam espaços nos contextos sociais de uso da língua.

Desse modo, ao se olhar para os textos, seja um pesquisador ou um professor, deve-se considerá-lo "como modo de enunciação (por meio do qual o sujeito põe em circulação outros pertencimentos, inclusive, em boa parte das pesquisas, pertencimentos de natureza social e histórica, que não aqueles concebidos abstratamente para todos)" (CORRÊA, 2015, p. 133).

Portanto, é possível sintetizar a visão de Corrêa (2007, p. 209) no seguinte excerto:

Em princípio, a sugestão, por exemplo, para a produção e a leitura do texto e para o trabalho com os gêneros discursivos seria a consideração dos processos de sua constituição e a valorização dos produtos percebidos como híbridos, que, em seu modo de produção de sentido, retomam, a meu ver, o dinamismo que marca a relação do sujeito com a linguagem. Basta constatar que os gêneros discursivos (orais e escritos) são produtos de relações intergenéricas (Bakhtin, 1992), as quais relativizam sua estabilidade e os repõem no dinamismo próprio da linguagem: o da mudança. 


\section{Metodologia}

O interesse inicial por esta pesquisa se deve, em primeiro lugar, a meu próprio contato, como pesquisadora e professora de Português em uma escola pública, com adolescentes do sétimo ano do Ensino Fundamental II que apreciavam escrever histórias e guardá-las em diários, caderninhos, ou mesmo publicá-las em sites e blogs da internet. Interessou-me a maneira como meus alunos pareciam desenvolver uma relação diferente com a escrita e, ao ter mais contato com as fanfics (histórias criadas por fãs a partir de um universo ficcional já existente), também passei a me interessar pela maneira como essas histórias circulavam na rede e jovens e adultos se mobilizavam para aprimorar sua escrita em um contexto em que consideravam significativo.

Chamaram-me a atenção o engajamento em práticas como a revisão de textos e a criação de espaços específicos com aulas de português, disponibilizadas pela própria comunidade de fãs. Sobretudo era interessante observar como esses jovens estavam aprendendo a escrever dialogando com seus colegas, trocando conhecimentos e opiniões a partir de comentários, desenvolvendo assim perspectivas próprias sobre as práticas de escrita e leitura. Com essas motivações, decidi então analisar, sob uma perspectiva dialógica, as fanfics escritas e publicadas em uma plataforma on-line.

Parti, assim, do seguinte problema de pesquisa: como os sujeitos realizam suas práticas de escrita no ambiente digital em contextos de comunidades de fãs, com quais práticas, gêneros e discursos dialogam?

Refletindo sobre esse problema original, foi necessário elaborar as questões de pesquisa. A questão principal da pesquisa é: como se caracteriza a escrita em comunidades de fãs e como diferentes discursos e linguagens se manifestam nos textos?

A partir dessa questão fundamental, surgiram novas questões, mais específicas, que, ao mesmo tempo, ajudaram a responder à questão central e auxiliaram a traçar objetivos mais específicos para a análise:

- Com quais gêneros, textos e discursos as fanfics selecionadas para a análise dialogam?

- Como os textos, discursos e gêneros de outras esferas e outras linguagens são assimilados e recriados dentro da comunidade?

- Como as fanfics dialogam com o contexto imediato de produção e respondem aos discursos que circulam na comunidade? 
A partir daí, foi traçado o objetivo da pesquisa: compreender, por meio da análise intergenérica de fanfics, como essa escrita dialoga com outros gêneros, outras semioses e outras culturas, considerando a forma composicional, o tema e o estilo do gênero. No entanto, devido à limitação de espaço deste artigo, foi feito um recorte de análise que considera apenas a forma composicional e o estilo do gênero, pois foi nessas duas dimensões que foram obtidos os resultados mais interessantes.

Os dados foram coletados da plataforma digital https://socialspirit.com.br/home/. Ela foi escolhida por ser o site brasileiro com maior número de publicações, a maioria em português e disponíveis gratuitamente, além do fato de estar no ar desde 2003, o que Ihe confere certa estabilidade necessária para o andamento de uma pesquisa, já que há poucos riscos de sair do ar. Esse espaço on-line se destinou, durante muito tempo, principalmente à escrita de fanfics relacionadas ao universo dos mangás (revistas em quadrinho japonesas de ampla circulação no Japão e, mais recentemente, no mundo), animês (animações japonesas) e games. Considerando essa história da plataforma, foram selecionadas fanfics de um animê bastante popular entre meninas e meninos nos anos 2000. Como o número de narrativas é muito grande, por razões metodológicas, foi necessário delimitar o número de textos analisados. Sendo assim, foram escolhidas fanfics publicadas entre 1 de julho de 2016 e 1 de janeiro de 2017, período de seis meses, por todos os escritores que publicaram dentro da categoria escolhida, com recorte em dois personagens da história. Há um grande número de fanfics que são iniciadas e não são finalizadas na plataforma. No entanto, para essa análise, foram selecionadas apenas as histórias consideradas terminadas por seus autores. No total foram analisadas nove shortfics (fanfics curtas, compostas por apenas um capítulo e menos de 1000 palavras) e uma longfic. Neste artigo serão analisadas apenas as shortfics.

Esta pesquisa é de caráter qualitativo e documental e procura mostrar como pessoas que não são escritores profissionais, e cuja escrita se afasta bastante daquela canonizada no meio literário, buscam uma maneira de se expressar e de produzir sentidos relevantes dentro de sua comunidade e das ideologias que a permeiam. São textos vinculados a culturas juvenis, muitas vezes também marginais e postas de lado por pesquisadores, mas que revelam aspectos interessantes sobre as novas/outras maneiras de os sujeitos se relacionarem com a língua e darem voz ao seu próprio discurso. Por dar visibilidade aos textos produzidos por jovens fora do contexto mais amplamente estudado, a sala de aula, essa pesquisa faz parte de uma demanda da área de Linguística Aplicada, que busca compreender como a escrita se relaciona a questões culturais e de identidade dos sujeitos.

\section{Análise dos dados e resultados}

A seguir será feita a análise das formas composicionais e dos estilos de gêneros das fanfics. Na conclusão serão feitas algumas considerações breves associando-as ao tema. 


\section{Análise das formas composicionais das shortfics}

Entre os fãs, as fanfics formadas por um único capítulo são chamadas oneshots. Elas parecem ser comuns entre escritores iniciantes, pois muitos autores dos exemplos lidos assumiram que estavam publicando pela primeira vez. Com relação à forma composicional, dois modos parecem prevalecer, os textos cuja forma composicional é predominantemente descritiva/reflexiva e os textos com enredo mais narrativo.

No primeiro caso, trata-se de histórias em que o fio narrativo é fraco e o desenrolar da história praticamente não acontece. São narrativas em que a tipologia textual descritiva é bastante preponderante. Tudo se passa em apenas uma única cena. Geralmente a fanfic começa com os personagens (já conhecidos pelos fãs) em uma determinada situação ou, mais comumente, refletindo sobre algo. Os personagens não são apresentados e o leitor que não os conhece tem a sensação de ter "pegado a história no meio". Nesse caso, é preciso conhecer a história original para entender as referências. É importante frisar que isso não acontece em todos os casos, há fanfics que podem ser lidas por autores que desconhecem a história original sem grandes prejuízos de sentido. Nesses casos, há uma maior autonomia da história.

Três fanfics, entre as analisadas, têm essas características mais descritivas ou reflexivas. A estrutura do texto lembra a de poesia, pois suas frases lembram versos, algumas vezes com algum ritmo. No entanto, no decorrer do texto, as frases vão ficando longas até formarem parágrafos. Parece que a escrita está no limite entre a prosa e o verso, como pode ser observado nos trechos (1), (2) e (3). Os espaçamentos foram mantidos como nos originais.

(1) Vim de outra época

Meu cabelo é mais curto que o seu.

O seu liso é liso e o meu é ondulado.

(2) Teu ódio te impede de veres através de minha alma e, por tanto, achas que minhas atitudes são falsas.

Esqueça-te deste rancor

(3) Desejo que sua alma encontre paz e que não odeies mais.

Odeia-me, derruba-me, pisa-me, mas, por favor, não me compare a você.

Parece que, nesse trecho, é possível falar de ruínas de uma forma composicional poética em um texto em prosa, ou talvez o contrário, um texto em prosa com ruínas de 
poema. É difícil definir, pois o texto mantém características das duas formas de maneira praticamente igualitária. É possível verificar, portanto, que há um diálogo das fanfics com textos da esfera literária.

Além dessas fanfics com formas composicionais descritivas, há aquelas que são predominantemente narrativas, em que o enredo se desenrola à medida que os fãs criam novas situações para os personagens do animê vivenciarem, seja uma continuação a partir da história original, seja uma história que se passa em um universo alternativo. Dentre esses textos, encontramos uma que é uma songfic. A letra de uma canção, The other woman, interpretada por diversos artistas, como Nina Simone e, mais recentemente, por Lana Del Rey, é alternada com o texto narrativo em prosa. A letra da música, que na fanfic está traduzida para o português, não apenas remete, mas complementa o conteúdo do texto, pois como a narrativa está em terceira pessoa e o narrador conta a história da perspectiva do personagem masculino, a letra da canção parece trazer o olhar da mulher envolvida na trama. Abaixo há um trecho em que isso pode ser observado. Foi mantida a formatação com sublinhado, como usado no original:

(4) Ela era aquela que o tirava da rotina, trazia luz a sua vida, luz que um dia kagome trouxe.

A outra mulher enfeitiça suas roupas com perfume francês

A outra mulher mantém as flores frescas em cada quarto

Nunca há brinquedos que está por toda parte

Não há créditos pela autoria das letras das canções, há apenas uma indicação com sublinhado e espaçamentos que faz com que o leitor suspeite que aqueles versos não são da autora. Provavelmente, haverá quem reconheça a canção, assim, espera-se uma relação de cumplicidade entre leitor e autor, que sabem do que se trata o elemento destacado sem que seja necessário que isso seja dito.

Do ponto de vista dialógico, é muito interessante esse imbricamento entre duas linguagens, a música (ou canção) e a narrativa. Nas animações japonesas, a música está sempre presente emoldurando as cenas e produzindo sentidos sobre os personagens e o cenário construído na trama. Os temas de abertura e encerramento das animações também são objetos cultuados pelos fãs e existem práticas que se relacionam mais com as músicas do que com as animações, como a prática de criação de AMV (Anime Music Video), clipes compostos de cenas de animês e músicas.

No entanto, a escrita, em princípio, não possui esse recurso, no máximo autores de literatura mencionam músicas e canções em seus textos que são tocadas ou cantadas dentro de uma cena. Mas nas fanfics há uma tentativa de transposição do elemento musical, típico do cinema e da televisão, para a palavra escrita. Para isso, os autores 
recorrem a conhecimentos partilhados dentro da comunidade de músicas que são conhecidas. Dessa forma, os escritores de fanfics conseguem criar um musical utilizando apenas linguagem verbal, por meio da justaposição de um texto em outro. Nesse caso, os autores criam um texto híbrido, a partir das linguagens musical e verbal, mostrando como novas formas composicionais são criadas nesses espaços digitais até se tornarem relativamente estáveis e passarem a se tornar populares. De qualquer forma, dois universos diferentes são colocados em diálogo, o que mostra a filiação e conexão do autor com esses dois mundos.

Além dos diálogos com gêneros poéticos e musicais, também foi possível notar um diálogo com biografias. Duas fanfics que fazem parte dos dados são escritas pela mesma autora. As duas têm como características passagens bastante reflexivas, mas há acontecimentos novos no desenrolar da história.

Há, portanto, uma hibridização gerada pelo diálogo entre dois gêneros diferentes, as fanfics e os relatos autobiográficos. Nesse caso não parece se tratar de ruínas de gêneros, pois parece que a autora quis explicitamente criar uma fanfic autobiográfica.

Entre essas narrativas também foi possível encontrar uma fanfic cuja forma composicional é a de um conto com toda a estrutura dos tradicionais contos de fadas, marcando, portanto, um diálogo com esse gênero. O "ruído" aparece pelo fato de os personagens terem nomes japoneses e a narrativa não ter um final feliz, típico dos contos de fada, pois o final da personagem em questão já era conhecido pelos fãs e a autora foi fiel ao animê. Assim, nessa narrativa, os personagens, que na história original eram personagens da mitologia japonesa, se transformam em reis e princesas, e o cenário passa a ser um luxuoso castelo medieval. Ou seja, há um imbricamento entre gêneros tradicionais ocidentais e orientais.

Do ponto de vista da forma composicional, também foi constatado um possível diálogo com narrativas audiovisuais: em alguns textos não havia narrador, assim como no cinema, na televisão, na animação e no teatro. Pôde-se também observar uma forma de se pontuar o texto em que a autora não usou o travessão da maneira como usualmente se faz em textos narrativos. Em vez disso, usou o nome do personagem para avisar o leitor que ele vai dizer algo, ou que está pensando algo, como pode ser visto no exemplo (5) em que o nome dos personagens marca o início da fala, como no texto teatral: 
(5)

Inuyasha

Estávamos nós viajando eu, kagome, mirok, sango, shippo e kirara quando encontramos pelo caminho um grupo de youkais lobos, e o líder do grupo também estava junto, ao chegarmos mais perto notei que o tal lider olhava muito para kagome me deixando muito irritado. Quando menos percebi lá estava ele na frente da kagome e segurando suas mãos.

_oi meu nome é kouga e o seu?

Kagome - o meu é kagome! Hahaha - disse meio sem graça.

Kouga - sabe como você é bonita!

Kagome - obrigada!

Inuyasha - ei largue elea agora mesmo! Quem você pensa que é?

Kouga - ele é seu namorado kagome! Nossa como você tem mau gosto ele tem cara de cachorro.

Inuyasha - cara de cachorro! Você vai ver quem aqui tem cara de cachorro! - disse o atacando.

Kagome - calma vocês dois! Se acalmem, inuyasha, senta!

Nisso, inuyasha caiu da cara no chão, kouga começou a rir de inuyasha o deixando ainda mais irritado - você me paga seu idiota!

Duas hipóteses sobre esse uso de pontuação são possíveis. Em primeiro lugar, podese pensar que os fãs escrevem assim por não dominarem ainda as convenções da escrita e experimentarem possibilidades aleatórias de pontuação. Em segundo lugar, pode-se pensar que, mesmo que os fãs não dominem as normas para pontuar diálogos em narrativas, busquem referências em suas experiências com outras linguagens. Consideramos que a segunda hipótese é a que mais está de acordo com a visão da heterogeneidade da escrita, que considera que as práticas orais e letradas estão relacionadas. Desse modo, é possível dizer que essa estrutura sem narrador, semelhante ao teatro, se deva ao fato de as fanfics dialogarem principalmente com objetos culturais da televisão e do cinema, onde geralmente há apenas personagens falando e não há narrador, ou seja, a cena prevalece. Dessa forma, o texto foi estruturado de tal maneira que lembra o texto dramático. Na última linha, na frase "Nisso inuyasha caiu de cara no chão..." aparece uma espécie de narrador, ou talvez deva ser chamado de rubrica, recurso utilizado nos textos teatrais para dar indicações sobre o cenário ou apontar mudanças na cena e nos gestos dos personagens. Visto que há apenas uma indicação da queda dos personagens e do riso, esse fragmento poderia ser considerado uma rubrica; no entanto, os verbos estão no passado, o que remete mais à voz de um narrador do que à de uma rubrica, já que na rubrica costuma-se utilizar os tempos verbais no presente. Assim, esse caso pode ser considerado uma ruína. Se o texto todo possui uma estrutura predominante sem narrador, devido à influência das diversas mídias e, apenas em momentos pontuais, aparece um narrador, significa que há uma ruína, um resquício 
das formas mais tradicionais e gráficas de narrar. Em outras palavras, a presença do narrador, tradicionalmente considerado normal para as narrativas, nesse texto aparece como desvio do padrão (padrão em relação à estrutura interna do texto, já que predomina a forma dramática). Ou seja, o conceito de ruína deve ser relativizado quando se trata dessas escritas inovadoras, pois ele depende da expectativa que as pessoas criam sobre um texto. Desse modo, se se espera, em um texto narrativo, a presença de narrador e personagens bem marcados, então, quando ele não apresenta isso, por influências de outros gêneros, vemos ruínas. No entanto, se a expectativa da comunidade não é ver textos necessariamente com narrador, então, se ele aparece uma única vez em trecho pequeno do texto, provavelmente, nesse caso, a presença do narrador é que será a ruína, considerando-se a lógica interna da forma composicional do texto.

\section{Análise do estilo do gênero nas shortfics}

Há predominância de dois estilos nos textos analisados: o primeiro é um estilo que dialoga com os gêneros literários, que se pode observar principalmente pela tentativa de se utilizar recursos poéticos, figuras de linguagem e determinadas escolhas lexicais; e o segundo é um estilo que dialoga com o universo das mídias, dos animês e da cultura de fã em geral, caracterizado como mais casual, coloquial, informal e utilizando enunciados carregados de sensualidade, erotismo e bom humor.

Nos exemplos (6), (7) e (8), há uma busca explícita por recursos literários e também por usos da linguagem, que procuram se distanciar dos usos cotidianos.

(6) "Não sei nem como agradece-lo senhor Sesshoumaru..."

(7) "As luzes que tem aqui dentro. Eu nunca apago as luzes. Elas piscam a noite toda, e eu as admiro"

(8) "Eu te amo tanto, mas tanto, que as minhas luzes querem ser seu coração, brilhante como o sol da manhã, e como as estrelas na noite"

O uso das comparações "como o sol da manhã" e "como as estrelas da noite" exemplifica o uso de figuras de teor literário. Os usos dos pronomes oblíquos, em "agradece-lo" e "eu as admiro", mostram essa tentativa de se adequar às normas padrão da língua portuguesa, mesmo isso não se concretizando.

Além da colocação pronominal pouco comum na oralidade, uma fanfic utilizou a conjugação clássica do verbo na segunda pessoa, o "tu", que hoje é restrito a algumas 
variedades linguísticas. Alguns autores defendem que o uso do imperativo negativo com essa conjugação se tornou tão restrito que é praticamente inexistente, como Bagno (2012, p. 570, grifo do autor):

[...] nem mesmo naquelas regiões onde encontramos o tu seguido da conjugação clássica (falas, falaste, falavas etc.)... os falantes dessas variedades jamais empregam o imperativo negativo previsto pelas gramáticas normativas. Ninguém no Brasil diz não venhas, não faças, não digas etc.

No trecho abaixo, pode-se ver o uso de "não odeies" e "odeia-me", exemplificando esse fenômeno:

(9) Desejo que sua alma encontre a paz e que não odeies mais.

Odeia-me, derruba-me, pisa-me, mas, por favor, não me compare a você.

Mesmo que consideremos que o uso dessa conjugação clássica com o "tu" no imperativo negativo não seja tão rara como defendem alguns autores, é preciso reconhecer, pela maneira como os escritores de fanfic têm usado e pelo contexto, que parece haver uma tentativa de rebuscamento da escrita.

Desse modo, a presença de usos estilísticos específicos mostra que há um diálogo com a escrita literária, que vem da percepção que os fãs têm sobre o que é escrever literariamente. O uso do "tu" acompanhado do verbo conjugado na maneira clássica é pouco utilizado no território brasileiro e restrito a algumas regiões. Pode ser que os autores sejam de uma região em que seu uso seja mais corrente, mas é mais provável que essa conjugação de segunda pessoa esteja sendo usada como recurso estilístico para se conseguir efeitos de sentido diferenciados na escrita.

Por fim, outra fanfic a ter um tom literário, a mesma que dialogava em sua forma composicional com os contos de fada, tem marcas específicas e recorrentes desse gênero, como a expressão "era uma vez" e o uso de comparações, hipérboles, metáforas e outros recursos de linguagem típicos do estilo do gênero, como "pele tão branca quanto a espuma do mar".

(10) Era uma vez uma princesa. A princesa mais bela dentre os quatro territórios governados pelos mais poderosos Yokais. Ela tinha a pele tão branca quanto a espuma do mar e seus cabelos eram igualmente brancos e enormes, um grande rio prateado que the corria pelas costas. 
Entre as fanfics cujo estilo de gênero é mais próximo à cultura de fã e aos produtos midiáticos vinculados a ela estão textos que se caracterizam por uma linguagem mais objetiva e próxima do cotidiano. No caso desta última, o autor fez o possível para aproximar ao máximo a fala dos personagens com as da animação:

(11) Inuyasha - cara de cachorro! Você vai ver quem aqui tem cara de cachorro! - disse o atacando.

Kagome - calma vocês dois! Se acalmem, inuyasha, senta!

As expressões "cara de cachorro" e "senta" são bastante utilizadas no animê por esses dois personagens em contextos parecidos. Portanto, nesse caso, há uma aproximação na linguagem com a história original que inspirou a fanfic.

\section{Conclusão}

Como, para Bakhtin (2011 [1978]), a forma composicional, o tema e o estilo não são três categorias estanques, pelo contrário, elas se inter-relacionam, é necessário fazer algumas considerações a partir da análise desses elementos. Em primeiro lugar, não é coincidência que as fanfics que têm uma forma composicional mais descritiva/reflexiva são exatamente aquelas em que há um diálogo com o estilo literário. Isso provavelmente acontece pela imagem que a comunidade de fãs tem da literatura, como textos em que acontece pouca ação e em que a linguagem assume um papel mais importante do que os acontecimentos do enredo. Embora o tema não tenha sido abordado neste artigo, é interessante pontuar que todas essas fanfics têm como tema principal o relacionamento amoroso, tema muito caro e extensivamente abordado na literatura.

Isso mostra que as fanfics que dialogavam com a esfera literária foram profundamente influenciadas por ela nos três elementos do gênero, na forma composicional, no tema e no estilo, o que vai ao encontro das afırmações de Bakhtin sobre o fato de o gênero discursivo ser determinado pela esfera. Foi possível verificar que existe também um diálogo entre essas esferas, que se manifestou nos enunciados concretos a partir de características genéricas. Portanto, as fanfics foram influenciadas pelo seu diálogo com a esfera literária, por exemplo, mas mantiveram suas características como fanfics devido ao lugar ocupado por elas no momento da enunciação.

Por outro lado, as fanfics que apresentaram formas composicionais mais centradas na ação dos acontecimentos narrativos, também apresentaram linguagem mais próxima do cotidiano e seus temas variaram mais para temas atuais, como preconceito e homossexualidade. De fato, essas fanfics que não apresentavam marcas do discurso literário em sua constituição estavam plenamente conectadas com a linguagem dos produtos audiovisuais da cultura de massa e, justamente, por isso, os diálogos se deram com música, com animês e mangás. 
Finalmente, é importante atentar para a heterogeneidade do gênero fanfic. Se Bakhtin (2011 [1978]) já apontava a dificuldade de se estabelecer pontos em comum entre os diversos gêneros, isso é mais verdade ainda para gêneros que se hibridizam com várias linguagens, como as fanfics que, além disso, dialogam com discursos e práticas advindas das mais diferentes esferas.

Como se pôde notar, elas não têm uma forma composicional estável. A forma composicional ora se aproxima da poesia, ora incorpora canções, ora se aproxima do conto de fadas, dialogando frequentemente com gêneros audiovisuais, para mencionar apenas os diálogos vistos nessa análise, pois, com certeza, o campo de possibilidades de criação de fanfics é muito maior do que essa pequena amostra analisada.

Portanto, não é possível definir as fanfics por características genéricas muito estáveis, já que os temas e o estilo também podem variar muito, segundo as experiências dos sujeitos com diferentes práticas e usos de linguagem. Parece, assim, ser mais seguro dizer que se trata de um gênero pertencente a um lugar de multiplicidade, o espaço digital.

\section{REFERÊNCIAS}

BAKHTIN, M. Estética da Criação Verbal. São Paulo: Martins Fontes, 2011 [1978].

BAKHTIN, M. Para uma filosofia do ato responsável. São Carlos: Pedro e João Editores, 2010.

BAGNO, M. Gramática pedagógica do português brasileiro. São Paulo: Parábola, 2012.

CORRÊA, M. G. Epistemologias na introdução e no desenvolvimento de práticas escritas: identidades em jogo. Delta, São Paulo, v. 31, p. 127-167, 2015. Disponível em: https://revistas.pucsp.br/delta/article/view/22222. Acesso em 30 jul. 2019.

CORRÊA, M. G. As perspectivas etnográfica e discursiva no ensino da escrita: o exemplo de textos de pré-universitários. Revista da ABRALIN, v. Eletrônico, n. esp., p. 333-356, $2^{a}$ parte, 2011. Disponível em: http://revista.abralin.org/index.php/abralin/article/ view/1115. Acesso em: 30 jul. 2019.

CORRÊAA, M. G. Encontros entre prática de pesquisa e ensino: oralidade e letramento no ensino da escrita. Perspectiva, Florianópolis, v. 28, n. 2, 625-648, 2010. Disponível em: https://periodicos.ufsc.br/index.php/perspectiva/article/ viewFile/2175795X.2010v28n2p625/18451 Acesso em: 30 jul. 2019. 
CORRÊA, M. G. Pressupostos teóricos para o ensino da escrita. Filologia e Linguística Portuguesa, São Paulo, n. 9, p. 201-211, 2007. Disponível em: https://doi.org/10.11606/ issn.2176-9419.v0i9p201-211. Acesso em: 30 jul. 2019.

CORRÊA, M. G. Relações intergenéricas na análise indiciária de textos escritos. Trabalhos em Linguística Aplicada, Campinas, v. 45, n. 2, p. 205-224, 2006. Disponível em: https://periodicos.sbu.unicamp.br/ojs/index.php/tla/article/view/8639432. Acesso em: 30 jul. 2019.

FARACO, C. A. Linguagem \& diálogo: as ideias linguísticas do círculo de Bakhtin. São Paulo: Parábola editorial, 2009.

JENKINS, H. Textual Poachers: television fans and participatory culture. New York: Routledge, 1992.

JENKINS, H. A Cultura da Convergência. São Paulo: Aleph, 2008.

MARCHEZAN, R. C. Diálogo. In: BRAIT, B. (org.). Bakhtin: outros conceitos-chave. São Paulo: Contexto, 2010.

SARTORI, A. T. Os professores e sua escrita: o gênero discursivo "memorial deformação". 2008. Tese (Doutorado em Linguística Aplicada) - Instituto de Estudos da Linguagem, Universidade Estadual de Campinas, Campinas. Disponível em: http://repositorio. unicamp.br/bitstream/REPOSIP/269810/1/Sartori_AdrianeTeresinha_D.pdf. Acesso em: 30 jul. 2019. 